\title{
The Deep History of the Scientific Study of Religious Thought and Behaviour
}

\author{
Donald Wiebe \\ Trinity College, University of Toronto
}

\begin{abstract}
This article provides a brief overview of the literature on transitions in modes of thought in the evolutionary development of our non-human and pre-historic human forebears. I will argue that this evolutionary history can account for the cognitive foundations underlying modern scientific modes of thought-dedicated to achieving 'disinterested' knowledge for its own sake—although not the actual historical emergence of the sciences. Essential to this task is understanding the continuities and discontinuities between human thought and that of our primate ancestors - the transitions in the cognitive capacities required for dealing with the physical environment - and the transformations essential for dealing with the increasing social complexities of our pre-historic human ancestors.
\end{abstract}

\section{Keywords}

Cognitive capacities; Modes of thought; Disinterested knowledge; Reason; Science;

\section{Contact Address}

Donald Wiebe, Professor Emeritus, 9 Douglas Ave, Toronto, Ontario, M5M 1G4, Canada, dwiebe@trinity.utoronto.ca

\section{Introduction}

It is generally understood that the field of scholarship widely referred to in the modern university as "religious studies" was a late nineteenth- and early twentieth-century creation of intellectuals interested in seeking a non-theological understanding of religious thought and behaviour. It differed from theological understanding of such thought and practice in that it was free from direct ecclesiastical control. In that sense, it was secular but not scientific in the sense the concept "science" obtained with and after the Scientific Revolution in sixteenth- and seventeenth-century Europe. In today's world, the notion of "scientific 
knowledge" - including the processes required for producing it - sets the benchmark for all epistemic claims made about the world and its contents.

The most obvious fact about this achievement is its late arrival in the life of Homo sapiens; it did not arrive on the scene, so to speak, with the arrival of anatomically modern humans. This is not, however, to deny that our evolutionary and historical forebears carried on in the world without knowledge of it and about it. But the knowledge they possessed was both less than and more than scientific and without understanding this it will not be possible even to give a reasonable account of the nature of "scientific study" itself, which is foundational to explicating what we mean by talk of the "scientific study of religion." My objective in this essay, therefore, is to provide an account of the evolution-the deep history - of the cognitive capacities of the human mind that ultimately led to the creation of scientific thought, the interplay between those cognitive capacities and the cultural realities they made possible, including religious thought and practice. I hope to accomplish this by way of a curated overview of the relevant literature on these topics.

The cognitive capacities of our hominin ancestors overlap to a great degree with their evolutionary forebears, but their social and cultural development produced a significant difference. Tracing those developments will require some awareness of the episodic cultures of early primate cognition, knowledge of the evolutionary transitions from the mind of our ape ancestors to species-specific modes of human thought, and knowledge of the prehistorical and historical transformations of those evolved human cognitive capacities that emerged under the pressure of cultural changes. On the one hand, our deep evolutionary history will be able to account for the cognitive foundations underlying the nature of scientific thought but not for its actual emergence in human culture. As cognitive archaeologist Steven Mithen points out, "[b]y the end of the last ice age the complete cognitive foundations for science appear to have been in place .... [but] the emergence of science as a discrete domain of behaviour is likely to have required a suite of social, historic, and economic circumstances that had not yet arisen in human history". ${ }^{1}$ A scientific mode of thought would have been irrelevant for dealing with the everyday issues facing our evolutionary and historical forebears, and perhaps even dangerous, given that carefully "thinking through" matters in response to the normal everyday dangers facing them could have been positively dangerous. In examining the archaic pre-historical phase of human cognitive development, on the other hand, it will become clear that religious thought, for example, had a significant role for archaic human communities in "make[ing] sense" of their world ... [by showing] how things in the universe cohere". ${ }^{2}$ This clearly suggests that the religious (mythopoetic) mode of thought long preceded the emergence of the science-like mode

\footnotetext{
${ }^{1}$ Mithen, Steven. Human Evolution and the Cognitive Basis of Science. In Peter Carruthers, Stephen Stitch, and Michael Segal (eds.). The Cognitive Basis of Science (23-40). (Cambridge: Cambridge University Press, 2002), 40 .

${ }^{2}$ Cohen, H. Floris. The Scientific Revolution: An Historical Inquiry. (Chicago: University of Chicago Press, 1994), 506.
} 
of thought that would require a peculiar set of social, political, and economic conditions for its establishment.

\section{Some Problematic Views on the Nature of Scientific Thought}

There is some literature relevant to my concern in this essay which I think potentially misleading in understanding the history of scientific thinking. I have in mind here, for example, Robin Dunbar's use of the concept of "science" in accounting for transformations of thought processes in our primate forebears and the application of the concept to describe the thinking of infants and children by Alison Gopnik, Andrew Meltzoff and Patricia Kuhl. These authors are reputable scientists and there is much to be learned from their experimental work, from the books to which I will refer, and from their other publications. Nevertheless, I find their use of the concept "science" to lack the nuance essential in accounting for the evolutionary and historical changes in human modes of thought that ultimately made possible the emergence of modern science.

In The Trouble With Science, Robin Dunbar, an anthropologist and evolutionary psychologist, maintains "that the scientific method is not merely typical of all humans, but is also a key feature in the lives of most birds and mammals", ${ }^{3}$ and he therefore calls them "nature's own scientists". ${ }^{4}$ Dunbar also maintains, as do some developmental psychologists, that children are "natural scientists". 5 This should be obvious, he maintains, because non-human animals like humans must be able to negotiate their way in their respective ecological niches or perish. Both humans and other animals, he insists, do so in a scientific way; that they have a method "for finding out about the world that combines empirical observation with causal inference". ${ }^{6}$ And insofar as they are able to do this, he argues, they are engaged in "low-level empirical [cook book] science" that permits them to learn about the regularities of their worlds which is essential to their wellbeing. Dunbar is well aware that science "does not consist simply of inductive generalizations"; that it "also consists of explanations for those empirical generalizations" ${ }^{8}$ Because of that awareness he claims that animals can "store information about the world in the form of hypotheses" and that they are able, therefore, to "use the rules of logic to make a leap of inference"' in responding to their changing environments. Drawing on the work of Claude Levi Strauss, Dunbar also claims that our hominin ancestors operated in a fashion beyond a mere "cookbook" type of science, often making "attempts at explanatory science as well". ${ }^{10}$ Dunbar, therefore,

\footnotetext{
${ }^{3}$ Dunbar, Robin. The Trouble With Science: Science, Magic, and Religion. (London: Faber and Faber), 1995, 58.

${ }^{4}$ Ibid, 59.

${ }^{5}$ Ibid, 79.

${ }^{6}$ Ibid, 55.

7 Ibid, 56.

${ }^{8}$ Ibid, 63.

${ }^{9}$ Ibid.

${ }^{10}$ Ibid, 56.
} 
concludes that "science is a genuine universal characteristic of all advanced life forms"; it "is something intrinsic to life itself ... [and] really is just plain simple learning of the kind with which we are all familiar". ${ }^{11}$

There can be no doubt that there is some continuity in the cognitive capacities of our primate forebears and those that ground the thought processes of modern human persons, but to claim that there is no significant difference between what Dan Dennett calls the "uncomprehending" thought processes of our primate forebears (which will receive attention below) and those that characterize modern scientific thought is not persuasive and can only hinder coming to a proper understanding of the nature of the modern sciences. The claim of Alison Gopnik and Andrew N. Meltzoff in their book Words, Thoughts, Theories "that the process of cognitive development in children are similar to, indeed perhaps even identical with, the processes of cognitive development in scientists" 12 is similarly problematic in coming to an adequate understanding of the origin and nature of the modern sciences. For them, children have the same theorizing abilities which continue into adulthood. ${ }^{13}$ Their argument that central elements of the scientific mode of thought are "a basic part of our evolutionary endowment" ${ }^{\text {" }} 4$ is beyond objection, as I will show below, but their further claim that "we can think of organized science as taking natural mechanisms of conceptual change, designed to facilitate learning in childhood, and putting them to use in a culturally organized way" fails to see how critically important cultural organization of those cognitive capacities are to the emergence of the modern sciences. The same criticism applies to the thesis in The Scientist in the Crib: What Early Learning Tells Us About the Mind by Alison Gopnik, Andrew N. Meltzoff and Patricia K. Kuhl. They write: "We think that children learn about the mind by being psychologists. They make predictions, they do experiments, they try to explain what they see, and they formulate new theories based on what they already know". ${ }^{15}$ These authors may be correct in pointing out "that babies and scientists share the same cognitive machinery" ${ }^{16}$ but they are not correct in suggesting, as I think they do, that babies and young children consciously "think, observe, and reason... [as well as] consider evidence, draw conclusions, do experiments, solve problems, and search for truth" in the way that modern scientists do. ${ }^{17}$ They acknowledge that babies and young children "don't do this in the self-conscious way that scientists do" but they do not seem to recognize the "gap" that scientific self-consciousness creates between the knowledge of the child and that found in the modern sciences.

\footnotetext{
${ }^{11}$ Ibid, 75.

${ }^{12}$ Gopnik, Alison, and Meltzoff, Andrew N. Words, Thoughts, and Theories. (Cambridge Mass.: MIT Press), 1997, 3.

${ }^{13}$ Ibid, 20.

${ }^{14}$ Ibid, 21.

${ }_{15}$ Gopnik, Alison, and Meltzoff, Andrew N., and Patricia K. Kuhl. The Scientist in the Crib: What Early Learning Tells Us About the Mind. (New York: Harper Collings), 1999, 55-56.

${ }^{16}$ Ibid, 199.

${ }^{17}$ Ibid, 13.
} 


\section{Cognitive Transformation in the Evolutionary Emergence of the Human Mind}

In The Prehistory of the Mind: The Cognitive Origins of Art and Science, Steven Mithen provides an overview of the emergence of the modern human mind by suggesting the evolutionary changes in brain structure and cognitive capacities of the many ancestors of Homo sapiens sapiens since its common ancestor with the chimpanzees six million years ago. In undertaking this task, Mithen depends heavily upon the work of evolutionary psychologists such as Leda Cosmides and John Tooby, rejecting the notion that the human mind acquires its contents entirely from its cultural environment. According to evolutionary psychologists, understanding the history of the evolution of the human mind can only be achieved in recognizing that the mind is not simply a blank slate and a general-purpose learning machine but rather that at birth it possesses a multiplicity of specialized mechanisms and cognitive processes that contain knowledge about the world hardwired in the brain's adaptation to its environment. Mithen, however, modifies the massive modularity thesis found in many evolutionary psychologists in his account of the emergence of the modern mind through the various evolutionary transformations of brain and mind in our ancestors from the Pleistocene and Palaeolithic to the Holocene.

Mithen looks at three phases in the emergence of the modern mind. The first is dominated by a domain of general intelligences of which little is known, the second phase is one in which that general intelligence is supplemented with specialized intelligences, each isolated in its own domain, and the third period is one in which the specialized intelligences-cognitive capacities — work together with a flow of knowledge and ideas between and among them. The intelligences, or cognitive capacities, of the second phase include a natural history intelligence, a technical intelligence, and a social intelligence concerned with understanding the natural world, the physical world, and their social interactions. These cognitive capacities arise from an intuitive knowledge of the natural world essential to life as hunter-gatherers, an intuitive physics necessary in making tools and other artifacts essential to their existence, and an intuitive biology essential in understanding and interacting with conspecifics, all of which are hardwired in their adaptation to a constantly changing environment. There was a continuous growth in these intelligences or cognitive capacities in humans from nearly two million to 100,000 years ago, but their isolation was overcome some 30,000 years ago, producing what Mithen calls a "cognitive fluidity" that allowed these different behavioural domains to influence each other. This in turn, as Mithen puts it, made possible new reflective ways of thinking and subjects to think about, which in turn enabled new and different ways of behaving. He writes, for example, that "... as soon as a language started acting as the vehicle for delivering non-social information and ideas into the domain of social intelligence, reflexive consciousness could also get to grips with the non-social world. Individuals could now become introspective about their non-social thought processes and knowledge. As a result, the whole of human behaviour was pervaded with the flexibility that is characteristic of Modern Humans" ${ }^{18}$ indeed, it "is the

${ }^{18}$ Mithen, Steven. The Prehistory of the Mind: The Cognitive Origins of Art and Science. (London: Thames and Hudson), 1999, 192. 
defining property of the modern mind". ${ }^{19}$ "The human mind," he writes in conclusion, "is a product of evolution, not supernatural creation ... [and] I have explained how the potential arose in the mind to undertake science, create art, and believe in religious ideologies, even though there were no specific selection pressures for such abstract abilities at any point during our past" ${ }^{20}$ This cognitive potential is the natural origin of both religious and scientific thought.

Merlin Donald also traces the evolution of the cognitive capacities of Homo sapiens in his book "Origins of the Modern Mind: Three Stages in the Evolution of Culture and Cognition," announcing in the Prologue to the book that the human mind is "a mosaic structure of cognitive vestiges from earlier stages of human emergence" and that its "cognitive architecture is highly differentiated and specialized" and not, therefore, a tabula rasa. ${ }^{21}$ Donald argues that there are three major evolutionary transitions from the minds of apes to that of modern humans, involving a complete redesign in the form of human thought and culture. Primate cognition, he points out, produces an episodic culture which he describes as lives "lived entirely in the present, as a series of concrete episodes, and the highest element of their system of memory representations seems to be at the level of event representation". ${ }^{22}$ Apes therefore have a great deal of situational knowledge but cannot represent those situations in order to reflect on them. Thus, even though apes have a degree of conscious awareness, Donald argues that " $[\mathrm{t}]$ he pinnacles of episodic [ape] culture [only mark] the starting point of the human journey". ${ }^{23}$ The first step towards the modern human mode of thought is from the episodic to a mimetic form of culture that gave rise to what Donald calls the archaic form of human culture of Homo erectus. The tool-making abilities of $H$. erectus, he claims, would have placed "demands on the intellect that go beyond the concrete, timebound episodic mentality" of the apes ${ }^{24}$ and created a culture "intermediate between the episodic mind and the symbolic representational systems of modern Homo sapiens. ${ }^{25}$ Homo erectus, therefore, would have been capable of representing many aspects of its physical and social environment relevant to its survival and expression of its intentions, although it would not have had the capacity for language. Donald maintains that this mimetic level of representation is foundational to modern human culture. The next major step towards that modern human culture for Donald involves the cognitive capacities that made possible the transition in cultures from mimetic to a mythic culture that begins with the emergence of our immediate human ancestor-archaic H. sapiens—about 200,000 years ago. Although little information about the earliest stages of this development is available, Donald points out that there is evidence of an important cognitive breakthrough about 50,000 years ago

\footnotetext{
${ }^{19}$ Ibid, 210.

${ }^{20}$ Ibid, 215.

${ }^{21}$ Donald, Merlin. Origins of the Modern Mind: Three Stages in the Evolution of Culture and Cognition. (Cambridge Mass.: Harvard University Press), 1991, 2-3, 5.

${ }^{22}$ Donald, Merlin. Origins of the Modern Mind: Three Stages in the Evolution of Culture and Cognition. (Cambridge Mass.: Harvard University Press), 1991, 159.

23 Ibid, 152.

${ }^{24}$ Ibid, 164.

25 Ibid, 161.
} 
with the development of cognitive innovations leading to the development of new tools and technologies that made possible cultural advantages for this species over other species. Most significant in this transition was the development of the capacity for speech, a 'tool' that increased our species capacity for cooperative behaviour and made possible an integrative mode of thought allowing the mind, as Donald puts it, to go "beyond the episodic perception of events, beyond the mimetic reconstruction of episodes, to a comprehensive modeling of the entire universe" ${ }^{26}$ It is a narrative mode of thought, then, that constructs myths to orient its place in the world - to 'make sense' of the world - that dominates the intellectual life of our hunter-gatherer forebears from about 40,000 to 10,000 years ago. In his A Mind So Rare: The Evolution of Human Consciousness Donald emphasizes how important this leap to language for creating a shared, collective account of reality was in the development of anatomically and behaviourally modern humans: "Once we have leaped into a narrative mind-set, our worlds become virtual ones.... Stories can become so influential and so deeply rooted in the daily operation of the culture that they assume a special cognitive status, that of myth.... This is an awesome power, unequaled in the history of cognition". ${ }^{27}$

A third major cognitive transition in human thought, Donald argues, marks a significant break from the earlier cultural patterns found in the evolution of our species which, he maintains, constitutes a significant "break with the dominances of spoken language and narrative styles of thought". ${ }^{28}$ Donald writes: "Three crucial cognitive phenomena appear to have been underdeveloped, or virtually absent, in oral-mythic culture. These phenomena are graphic invention, external memory, and theory construction", ${ }^{29}$ which make possible "formal arguments, systematic taxonomies, deduction, verification, differentiation, quantification, formal methods of measurement, etc." ${ }^{30}$ that, ultimately, leads to the disenchantment of mythic thought, though not necessarily to its total abandonment. As the narrative/mythic mode of thought/mind gave rise to religious thought, even though it also "signalled the first attempts at symbolic models of the human universe", ${ }^{31}$ so the new theoretic mode of thought ultimately made possible modern scientific thought. Before leaving discussion of Donald's account of the emergence of the modern mind it must, however, be pointed out that his theory reveals that the modern human mind is the product of multiple levels of awareness - a cascade of stages in the evolution of Homo sapiens. And each successive stage in that evolution has magnified the previous stage and significantly changed the culture associated with each. It is clear, therefore, that human cognitive capacities are not simply biological phenomena but also, in some sense, socio-cultural forces. It is also the case that, under a specific set of psychological or socio-political conditions, either one or the other

\footnotetext{
${ }^{26}$ Ibid, 214.

${ }^{27}$ Donald, Merlin. A Mind So Rare: The Evolution of Human Consciousness. (New York: W. W. Norton \& Company), 2001, 295.

${ }^{28}$ Ibid, 269.

${ }^{29}$ Ibid, 272.

${ }^{30}$ Ibid, 274.

${ }^{31}$ Ibid, 267.
} 
of these modes of thought, or a hybrid mode of the two, may play a dominant role in response to a new set of economic, social, or political conditions in society.

It is important in discussing the development of human modes of thought to recognize that there is no radical discontinuity with that of $H$. sapiens' forebears. As Michael Tomasello insists, in order to understand the uniquely human mode of thought it must be situated in its evolutionary context. We need to keep in mind that human thought processes depend upon the mental predispositions we have by way of natural selection in our ancestors' interaction with the physical world, including such basic cognitive capacities as perception, memory, and the capacity to conceptualize and categorize. These predispositions can be thought of as hardwired templates in the mind in terms of which we automatically respond to events in our environment. As Mithen pointed out, these predispositions, as specialized types of intuitive knowledge, were gained not by individual experience but rather, were hardwired into the brain in our evolutionary development. And such intuitive 'knowledges' constitute what we now generally refer to as "folk knowledge". Cognitive scientists generally posit four such types of folk knowledge: (i) Folk Physics which includes "understanding" physical and mechanical causal connection clearly important with respect to natural hazards; (ii) Folk Biology which includes knowledge of biological phenomena of growth and decay and makes possible differentiating animacy and agency from physical objects and artifacts; (iii) Folk Psychology which makes possible distinguishing intentionality from mere agency; and (iv) Folk Sociology or social intelligences and the capacity for cooperative and social existence. Such hardwired knowledges were essential in our evolution in making possible rapid responses to dangers in our evolutionary environment of adaptation and ensuring appropriate social interaction with each other. However, as Merlin Donald points out, our forebears also moved beyond these shared cognitive capacities with the emergence of language and with it the transition from mimetic to a mythic mode of cultural development and, finally, to a transition to a complex symbolic culture which, ultimately, was conducive to scientific thought. It is the unique, species-specific, character of these later developments in modes of human thought that Tomasello sets out in a series of studies as discontinuous, "[t]o an unprecedented degree," with what preceded it: The Cultural Origins of Human Cognition (1999), Origins of Human Communication (2008), Why We Cooperate (2009), A Natural History of Human Thinking (2014), A Natural History of Human Morality (2016) and, Becoming Human: A History of Ontology (2019). Tomasello argues that "...the changes we see in human societies beginning with the advent of agriculture and cities are not due, on anyone's account, to any kind of biological adaptation. The changes would seem to be sociological only.... [They] are built primarily on cooperative skills and motivations biologically evolved for small-group interaction". ${ }^{32}$

According to Tomasello, it is the social dimensions of human thinking, involving joint and collective intentionality that created "an identifiably different type of thinking" in $H$.

32 Tomasello, Michael. Why We Cooperate. (Cambridge Mass.: MIT Press), 2009, 104. 
sapiens, from that of their primate forebears living in competitive societies. ${ }^{33}$ Such shared intentionalities, that is, make possible processes of social coordination-a kind of cultural cognition. Without an awareness of the critical nature of these kinds of social interaction, he argues, there would be no possibility of becoming "objective"-in the sense of overcoming our multiple individualistic perspectives-or accounting for science. In this regard, Tomasello rejects Gopnik's views that children behave like scientists because it is "insufficiently social". ${ }^{34}$

In A Natural History of Human Thinking Tomasello writes: "In order to survive and thrive, humans were forced, twice, to find new ways to coordinate their behavior with others in collaborative (and then cultural) activities and to coordinate their intentional states with others in cooperative (and then conventional) communication. And this transformed, twice, the way that humans think". ${ }^{35}$ The first transition involved the "creation of a novel type of small-scale collaboration in human foraging" including pointing, gesturing, and pantomiming, and the second emerged because of inter-group competition wherein "group life as a whole became one big collaborative activity, creating a much larger cultural ground via collectively known cultural conventions, norms and institutions" ${ }^{36}$ It was a change of ecology about 400,000 years ago that effectively brought about the first transition. The radical changes in the environment, Tomasello argues, required greater interdependence among hominins in that period than ever before in procuring their daily sustenance which forced them to develop new forms of cooperative communication in foraging and scavenging activities. This clearly involved greater social coordination among members of the band that exceeds the intentionality of what he calls the cognition for competition that characterized great ape social activity. ${ }^{37}$ The need for early humans to be able to make judgments about potential collaborative partners, he argues, brought about "a uniquely human form of [what Tomasello calls] second-personal joint engagement requiring species-specific cognitive skills and motivational propensities". ${ }^{8}$ Thus, whereas the great apes make individual decisions with respect to obtaining food, members of the genus homo make joint decisions with others "in which two individuals engage with the intentional states of one another both jointly and recursively". ${ }^{39}$ Thinking here was not, however, fully socially normative because the partners in such a "we-intentional" act "were concerned [only] with how their

\footnotetext{
${ }^{33}$ Tomasello, Michael. A Natural History of Human Thinking. (Cambridge Mass.: Harvard University Press), 2014,4 .

${ }^{34}$ Tomasello, Michael. Becoming Human: A History of Ontogeny. (Cambridge Mass.: Harvard University Press), 2019, 85.

35 Tomasello, Michael. A Natural History of Human Thinking. (Cambridge Mass.: Harvard University Press), 2014, 10.

${ }^{36}$ Ibid, 5.

${ }^{37}$ Ibid, 26-27.

${ }^{38}$ Ibid, 43.

${ }^{39}$ Ibid, 47.
} 
partner evaluated their cooperative behavior and comprehended their communicative acts, not with the group's normative standards". ${ }^{40}$

The second transition, occurred about 200,000 years ago, with the emergence of a collective intentionality which amounts to creating cultural conventions in which the group, as Tomasello puts it, 'became more than a loosely structured pool of collaborators ..., [becoming instead] self-identified cultures with their own 'histories". ${ }^{41}$ Humans now thought in terms of cultural conventions, norms, and institutions that involved "effacing of one's own perspective in deference to the more 'objective' perspective of others in the group". ${ }^{42}$ The 'objectivity' here is not that of the modern sciences but refers rather to the existence of social and institutional facts which are objective facts about the world in which modern humans function even though, as Tomasello puts it, they are "observer relative" facts, "created by individuals in social groups," and can, unlike physical facts, be dissolved by individuals in social groups. ${ }^{43}$ Tomasello therefore concludes that "[h]uman thinking has [at this stage] become collective, objective, reflective, and normative; that is to say, it has now become full-blown human reasoning". ${ }^{44}$ Humans, Tomasello argues in his Becoming Human, unlike apes, do not use one another as social tools. Rather, through joint and collective intentional activities they have become "cooperatively dependent" on one another which has created uniquely human "supraindividual social structures". ${ }^{45}$

\section{The Prehistory of Science}

In "Human Evolution and the Cognitive Basis of Science," Steven Mithen, somewhat like Robin Dunbar, maintains that we must recognize that the foundations of science go back at least as far as our common ancestor with the great apes. He maintains, for example, that they "most likely already engaged in hypothesis testing and made acute observations about the natural and social worlds". ${ }^{46}$ Unlike Dunbar, however, he does not credit our non-human ancestors with science, even of the empirical cookbook variety. Rather, he maintains that the "capacity for science [cannot] be entirely reserved for modern humans [because] several of our ancestors employed, and were perhaps reliant on, key elements of scientific thinking for their survival". ${ }^{47}$ Some of those "key elements" match those referred to by Dunbar, such as making extensive and detailed observations of the natural world, using tools to extend

\footnotetext{
${ }^{40}$ Ibid, 79.

${ }^{41}$ Ibid, 84.

42 Ibid, 122.

${ }^{43}$ Ibid, 91.

${ }^{44}$ Ibid, 123.

45 Tomasello, Michael. Becoming Human: A History of Ontogeny. (Cambridge Mass.: Harvard University Press), 2019, 318.

${ }^{46}$ Mithen, Steven. Human Evolution and the Cognitive Basis of Science. In Peter Carruthers, Stephen Stitch, and Michael Segal (eds.). The Cognitive Basis of Science (23-40). (Cambridge: Cambridge University Press), 2002, 40.

47 Ibid, 24.
} 
human perception, showing concern with causation, generating and testing hypotheses, and accumulating knowledge over time. Mithen recognizes that such capacities have been employed at various stages of hominid and early human development. ${ }^{48}$ However, whether societies that made use of these various capacities in one way or another in that evolutionary development should be described as possessing science Mithen writes: "It is a moot point, one that depends upon how the term is defined". ${ }^{49} \mathrm{He}$ sees the evolutionary development of such capacities in the eventual emergence of $H$. sapiens more cautiously as transitions in modes of thought. Early hominids, for example, show continuity with the great apes in their possession of a detailed knowledge of their natural environments involving drawing generalizations and the making of tools. But none of this for him really amounts to being scientific knowledge. He acknowledges that early humans, even though still prelinguistic, possessed an understanding of causation but notes that this kind of knowledge was generally restricted to their social world. Extension of such causal thinking to the natural world, he admits, would have constituted scientific thought, but this, he insists, was not present in their thinking. Mithen notes that in their daily lives, Neanderthals, for example, were engaged in "planning, hypothesis testing, and meticulous observation of the natural world" but that this did not amount to an accumulation of knowledge over time. Mithen also points out that $H$. sapiens emerging in Africa about 130,000 years ago displayed a very different type of mentality-yet another transition in thought that can reasonably be seen as the emergence of a new mode of thought. Anatomically modern humans according to him, that is, possessed a more complex language than their forebears, which made possible the emergence of a symbolic culture with a greater ability to invent and make use of technology. Nevertheless, not even in this context, according to Mithen, does one find the emergence of a scientific mode of thought but only the development of further foundations necessary for the emergence of science.

It is clear, therefore, that even if, as Mithen claims, all of the cognitive developments essential to the emergence of scientific thinking were in place by the end of the last Ice Age, that would not constitute evidence that scientific thinking actually existed in those societies. The new cognitive capacities that developed over time from the early hominids to anatomically modern human beings made possible significant technological advances, but they did not give birth to scientific thinking. As Mithen puts it: "While the mixing of pigments, construction of dwellings, planning of foraging activities and the reading of tracks may have involved scientific modes of thought, these were most likely also intimately tied into religious beliefs which many would consider the precise opposite of scientific thinking" ${ }^{50}$ Despite the ambiguity in his reference here to "scientific modes of thought" rather than simply "elements" of a scientific mode of thought, Mithen concludes by saying that "the emergence of science as a discrete domain of behaviour is likely to have required a suite of social, historic and economic circumstances that had not yet arisen in human

\footnotetext{
${ }^{48}$ Ibid. 24

${ }^{49} \mathrm{Ibid}, 37$.

${ }^{50}$ Ibid, 37.
} 
history"; ${ }^{51}$ a suite of behaviours involving "a very particular set of social and economic circumstances leading to an isolation of ... [the religious and scientific] modes of thought from one another". ${ }^{52}$

Interestingly, Tomasello denies that there is a radical discontinuity between our thought and that of our evolutionary forebears and yet also maintains that the human form of thinking is unique. For him, "With modern humans and their skills of conventional linguistic communication, we get to full-blooded reasoning, where 'reasoning' means not just to think about something but to explicate in conventional form - for others and oneself-the reasons why one is thinking what one is thinking". ${ }^{53}$ In his Becoming Human, Tomasello draws on work by Hugo Mercier and Dan Sperber showing that this emerges from the perceived need of "epistemic vigilance" where one does not know everyone in the group of which they are members. "In this kind of social context," he writes: 'one could not expect others to accept a perspective or argument on trust. Individuals therefore started giving others reasons for why they should believe what they were telling them, typically pointing out facts that supported their view. Giving reasons in this way is a normative enterprise because it does not involve one individual attempting to overpower or coerce another into believing something, but rather it involves a third element—an impartial fact that does not depend on one's point of view-to adjudicate: 'you do not have to take my word for it, just consider for yourself this reason"'. ${ }^{54}$

Thus, although claiming that this does not amount to a radical discontinuity of human thought from that of their evolutionary forebears, Tomasello nevertheless insists that human thought is "much more complex than the cognition and thinking of other primates" 55 and is therefore uniquely human. Although he points out that the processes of joint and collective intentionality that characterizes human thought at this stage "are universal in the human species," he also notes that they were expressed differently in different groups of humans because of "culturally specific cognitive skills and ways of thinking for their own local purposes".${ }^{56}$ Tomasello, no more than Mithen, then, believes that prehistoric human thought is a form of scientific thinking because it is not a mode of thought dedicated simply to achieving disinterested knowledge about the physical world but was selected for its role in supporting cooperative human behaviour of which little is seen in our evolutionary ancestors. However, like Mithen, Tomasello makes clear that the forms of "Western science

\footnotetext{
${ }^{51}$ Ibid, 40 .

52 Ibid, 37.

53 Tomasello, Michael. A Natural History of Human Thinking. (Cambridge Mass.: Harvard University Press), 2014, 110.

${ }^{54}$ Tomasello, Michael. Becoming Human: A History of Ontogeny. (Cambridge Mass.: Harvard University Press), 2019, 171.

55 Tomasello, Michael. A Natural History of Human Thinking. (Cambridge Mass.: Harvard University Press), 2014, 124.

56 Ibid, 141.
} 
and mathematics," as he puts it, would simply not have been possible without these earlier evolutionary cognitive developments. ${ }^{57}$

In The Enigma of Reason, Hugo Mercier and Dan Sperber, like Tomasello, recognize the need to provide an evolutionary explanation for reason and reasoning as another peculiar human cognitive mechanism. "While reason has obviously benefited from various cultural enhancements," they write, "the very ability of a species to produce, evaluate, and use reasons cries out for an evolutionary explanation". ${ }^{58}$ Reason, they argue, is not synonymous with logic; it is rather a special form of inference which is the basic avenue to obtaining knowledge that goes beyond the power of the senses. They maintain therefore that an intellectualist approach that understands reason as a kind of "cognitive add-on" is simply unable to overcome the failure of past "sophisticated reasoning on reasoning ... [in] providing a consensual understanding of reasoning itself" ${ }^{59}$

Mercier and Sperber therefore reject the common sense picture of reason as providing the foundation for our beliefs and actions which, they point out, is not supported by the evidence. It is modules in the human brain that produce unconscious inferences that generate many of our beliefs and motivates human action. These modules have no need for reason in performing these functions and reason's role in human thought, therefore, must be sought elsewhere. Reason comes into the picture only after beliefs are formed-its true role being to justify the epistemic claims, and actions based on them. As Mercier and Sperber put it, "reasons are for social consumption"; ${ }^{60}$ they are of great importance as aids to cooperative social interaction. They write: "Reason, we argue, is a mechanism of intuitive inferences about reasons to justify themselves and to convince others, two activities that play an essential role in their cooperation and communication .... [R] eason evolved as an adaptation to a very special ecological niche, a niche that humans built and maintain for themselves with their intense social relationships, powerful languages, and rich culture". ${ }^{61}$

Cooperative social interaction is essential in every society and its members will be called upon to justify the claims they make about the world and the behaviors in which they engage. So, "reason didn't evolve to enhance thinking on one's own but as a tool for social interaction"; ${ }^{2}$ it evolved for providing good reasons for a reticent audience for one's beliefs and actions. Reason, therefore, is a 'reputation management mechanism' to protect one's reputation as a solid citizen. Mercier and Sperber write: "By giving reasons to explain and justify yourself, you do several things. You influence the way people read your mind, judge your behavior, and speak of you. You commit yourself by implicitly acknowledging the normative force of the reasons you invoke. You encourage others to expect your future behavior to be guided by similar reasons (and to hold you accountable if it is not).

\footnotetext{
${ }^{57}$ Ibid, 141, 142.

${ }^{58}$ Mercier, Hugo, and Sperber, Daniel. The Enigma of Reason. (Cambridge Mass.: Harvard University Press), 2017, 3 .

${ }^{59}$ Ibid, 21.

${ }^{60}$ Ibid, 123.

${ }^{61}$ Ibid, 107.

${ }^{62}$ Ibid, 333.
} 
You also indicate that you are likely to evaluate the behavior of others for reasons similar to those you invoke to justify yourself. Finally, you engage in a conversation where others may accept your justifications, question them, and invoke reasons of their own, a conversation that should help you coordinate with them and from which shared norms actually progressively emerge". ${ }^{63}$

Given this account then, reason is not itself a module in the brain. What has evolved, rather, is a more modest module - an intuitive inference module that produces intuitions about reasons ${ }^{64}$ Reason, that is, did not evolve to be used by philosophers and metaphysicians, or in courts of law; rather, it evolved to be used in the informal contexts of people exchanging many short arguments in support of particular beliefs and actions.

Having provided a scientific account of reason and reasons, Mercier and Sperber nevertheless speak "in praise of reason" in their conclusion. They claim to have put reason "back where it belongs, level with other cognitive mechanisms." But they acknowledge as well that, like other evolved cognitive mechanisms, reason is not only as complex, subtle, and powerful as they are, but that it "may well be the most original and characteristic feature of the human mind". ${ }^{65}$ In addition to its social function, they point out that "reasons" can "produce reflective conclusions about the things reasons are themselves about" ${ }^{66} \mathrm{In}$ this respect reason can "exploit properties of reason in general [like] relevance, clarity, or strength" as well as specific types of reasons [such as] the force of precedent in reasons concerning coordination, from parent-children relationships to legal matters" ${ }^{67}$ This makes reason useful not only for justifying oneself but also for "evaluating the arguments others produce to convince us" ${ }^{68}$ And they admit that this kind of back-and-forth argumentation is something scientists can make use of in distinguishing good from bad argumentation in justifying knowledge claims about the world and its contents. In fact, philosophers of science like Karl Popper, for example, sees scientific knowledge as the product of just such a back-and-forth process he calls conjectural-refutational thinking.

\section{Contrasting the Scientific Thought Style to Pre-Scientific Thought}

This brief overview of the various transitions in the modes of thought in the evolutionary development of our non-human and pre-historic human forebears provides no evidence that any of them possessed something like our modern mode of scientific thought. There is simply no indication in that deep or proximate history of $H$. sapiens of the existence of a mode of thought that characterizes the modern sciences as they emerged in Europe in

\footnotetext{
${ }^{63}$ Mercier, Hugo, and Sperber, Daniel. The Enigma of Reason. (Cambridge Mass.: Harvard University Press), 2017, 185-186.

${ }^{64}$ Ibid, 200-201

${ }^{65}$ Ibid, 91.

${ }^{66}$ Ibid, 329.

${ }^{67}$ Ibid.

${ }^{68}$ Ibid, 332.
} 
the sixteenth and seventeenth centuries. Even though all the cognitive capacities necessary for genuine scientific thought are there, it is clear that what Claude Lévi-Strauss and others have referred to as the "science of the concrete" or "archaic science" is essentially a matter of a new technology and not science. Lewis Wolpert, for example, writes in his The Unnatural Nature of Science: Why Science Does Not Make (Common) Sense: "The technological achievement of the ancient cultures was enormous, and Lévi-Strauss is right to pose the question of how it was achieved. But whatever process was involved, it was not based on science. There is no evidence of any theorizing about the processes involved in the technology nor about the reasons why it worked: for example, it was enough to know that adding charcoal to the molten mixture would accelerate the smelting of iron. Metalworking was an essentially practical craft based on common sense. The goals of the ordinary person in ancient times were practical ends such as sowing and hunting, and that practical orientation does not serve pure knowledge. Our brains, that is, were selected to help us survive in a complex environment; the generation of scientific ideas play no role in this process". ${ }^{69}$ Wolpert acknowledges that the centuries of learning through methodical observation and testing of hypotheses in archaic technological creations "makes it seem that primitive technology involved processes very similar to those of science," but, like Mithen and Tomasello, he points out that that learning process did not require theorizing of the kind found in the modern sciences. ${ }^{70}$ Wolpert, that is, rightly recognizes that our cognitive capacities were selected for dealing with our immediate environment and that the slow processes of critical reflection and scientific theorizing would have been useless in responding to the immediate needs of our forebears and dangerously slow in responding to the immediate dangers in their environment. In that context, he insists, seeking scientific understanding of the physical world would have been unnatural. ${ }^{71}$

Historian Richard W. Bulliet also provides a particularly cogent and insightful critique of this notion of archaic science in his Hunters, Herders, and Hamburgers: The Past and Future Human-Animal Relationships where he shows why Lévi-Strauss's account of the domestication of animals was not the achievement, as Lévi-Stauss puts it, of a "genuinely scientific attitude, sustained and watchful interest and a desire for knowledge for its own sake" ${ }^{72}$ Bulliet remarks: "What prompts Lévi-Strauss to postulate early man engaging in a special type of long-term scientific thinking and experimentations is, in the specific case of animal domestication, his assumption that humans desired to derive material uses, 'nutritious or technologically useful properties,' in his words, from captive wild stock and could only be achieved through prolonged experimentation and observation, an application of 'scientific thinking' and a quest for 'knowledge for its own sake' seems to be the

${ }^{69}$ Wolpert, Lewis. The Unnatural Nature of Science: Why Science Does Not Make (Common) Sense. (Cambridge Mass.: Harvard University Press), 1993, 27.

${ }^{70}$ Ibid, 26.

${ }^{71}$ Ibid, 11.

72 Bulliett, Richard W. Hunters, Herders, and Hamburgers: The Past and Future of Human-Animal Relationships. (New York: Columbia University Press), 2005, 102. 
only answer. But would this assumption of a brief but amazingly productive spurt of scientific thought in Neolithic time have been required if affective uses had been taken into account"? ${ }^{73}$ Bulliet says no. As he puts it: "A cardinal difference between affective uses and material uses is immediate gratification. The warm feeling, we get from playing with baby animals requires no time lapse and no quest for knowledge for its own sake. Nor does it require domestication. A baby wild animal is just as cuddly as a baby domestic animal. ... Historically, therefore, if immediately gratifying some sensibility played a significant role in prompting people to keep some specimens of a particular species captive over many generations, it might be possible to explain the eventual emergence of the genetic tameness in that species without recourse to theories of prehistoric scientific thought and a quest for knowledge for its own sake. In this scenario, the exploitation of products, talents, and labor would constitute subsequent discoveries arising well after the species had become genetically tractable" ${ }^{74}$

Understanding the deep history of the human mind as a cascade of cognitive capacities, with each successive stage in the evolution of $H$. sapiens increasing the range of knowledge available to the species, will make it possible for us to account for what anthropologist and philosopher Ernest Gellner calls the great gap between the primitive and the modern mind. Gellner describes this development in his essay "An Ethic of Cognition" as "the biggest, most conspicuous simple fact about the human world". ${ }^{75}$ Without recognizing that fact, the different cognitive capacities employed in primitive/archaic and modern communities, he argues, it will be impossible to understand the emergence and persistence of "religion" (religiosity and religions) or a scientific study of religion. In Gellner's essay "The Savage and the Modern Mind," he clearly spells out four distinctions between contemporary "primitive" and modern modes of thought. The first is the use of idiosyncratic norms in primitive thought in which norms are espoused that have both epistemic and moral import simultaneously. The scientific outlook of modern western societies is mechanistic, rather than "agentic" or "enchanted," and therefore is in conflict with traditional societies' provisions of a meaningful world-picture framed by their use of idiosyncratic norms - its "bending of the regularity expectations in the interest of the local status system ...," as Gellner puts it. ${ }^{76}$

A second crucial distinction, Gellner argues, is found in the low cognitive division of labour found in primitive societies, which is accompanied by a proliferation of roles for individuals in such societies. The agentic or enchanted vision works, he argues, "through the systematic conflation of descriptive, evaluative, identificatory, status-conferring, etc. role of language [and that] a sense of the separability and fundamental distinctness of the

\footnotetext{
${ }^{73}$ Ibid, 103.

${ }^{74}$ Ibid, 105.

${ }^{75}$ Gellner, Ernest. An Ethic of Cognition. In Ernest Gellner, Spectacles and Predicaments: Essays in Social Theory (162-181). (Cambridge: University of Cambridge Press), 1979, 175.

${ }^{76}$ Gellner, Ernest. The Savage and the Modern Mind. In Robin Horton and Ruth Finnegan (eds.). Modes of Thought (162-181). (London: Faber and Faber), 1973, 172.
} 
various functions [originally and innocently introduced as a neutral analytical device], is the surest way to the disenchantment of the world" ${ }^{77}$ In the modern context, once concepts become tools for explanation they cannot be allowed, on pain of the loss of coherence and efficiency, to be tools for other purposes. Gellner illustrates this point by showing how empiricist thought, for example, has discouraged what he calls "boundary-hopping" in the use of the same concept with respect to matters in the physical and transcendent worlds. "Orderly and regular conduct," he writes, "is exacted from concepts, as it is from people". ${ }^{78}$

A third crucial area of distinction between the primitive and modern modes of thought Gellner maintains is the diffused and persuasive quality of what he calls the entrenched clauses of the intellectual constitution of the primitive mind. Gellner is fully aware that all societies have such entrenched clauses, ("sacred," that is, untouchable and unquestionable claims), but are much more numerous and extensive in primitive societies. In modern societies, he writes, "much less of the fabric of life and society benefits from reinforcement from the sacred or entrenched convictions". ${ }^{79}$

"Diplomatic immunity of cognition" is Gellner's rubric for a fourth significant distinction between the primitive and modern modes of thought. By "cognitive immunity" Gellner means that in modern societies ever greater areas of knowledge acquire autonomy from "the social, moral, and political obligations and decencies of society".$^{80}$ In primitive societies, as he points out, knowledge claims are subject to the same kinds of obligations and sanctions as are other kinds of conduct, whereas in modern societies this is not so-knowledge claims are not controlled according to the effects they may have, for example, on faith claims. This is especially important since such epistemic autonomy does not mean that epistemically justified knowledge claims are not necessarily philosophically (or religiously) neutral and can, therefore, and often do, come into conflict with the entrenched clauses of older traditional belief-systems. That is precisely why knowledge claims require autonomy relative to the social, political, moral, and religious orders of society. Thus, as Gellner puts it in his "Pragmatism and the Importance of Being Earnest," "what distinguishes the scientific thought style from pre-scientific ones is notably the fact that instead of satisfying many criteria -including social cohesion, authority-maintenance, morale, etc.-it sheds all but one, i.e., explanatory power and congruence with the facts". ${ }^{81}$

It is clear from Gellner's analysis of primitive/archaic thought that there exists a great gulf between it and the scientific mode of thought found in modern human society. And he argues that an explanation for the steps in our evolution that ultimately made possible the emergence of our modern sciences is necessary. As noted above, Tomasello has pointed out that we see in the flourishing human cultures found in Europe by 40,000 years ago

\footnotetext{
77 Ibid, 174.

${ }^{78}$ Ibid, 176.

${ }^{79}$ Gellner, Ernest. The Savage and the Modern Mind. In Robin Horton and Ruth Finnegan (eds.). Modes of Thought (162-181). (London: Faber and Faber), 1973, 178.

${ }^{80}$ Ibid, 176.

${ }^{81}$ Gellner, Ernest. An Ethic of Cognition. In Ernest Gellner, Spectacles and Predicaments: Essays in Social Theory (162-181). Cambridge: University of Cambridge Press, 1979, 55.
} 
a full-blooded mode of thinking that rested on modern human skills and capacities for linguistic communication which provides the potential for the emergence of a science-like mode of thinking but does not itself amount to scientific thinking. It appears, moreover, that it is precisely the narrative mode of human thinking that made possible that full-blooded mode of thinking that also constituted a road-block of sorts to moving from a mythic to a theoretic/scientific stage of human thought. The transition from mimetic to mythological thinking, Donald points out, created "a predominantly narrative mode of thinking": 82 "Group narrative skills," he writes, "leads to a collective version of reality; the narrative is almost always public". ${ }^{83}$ This is a type of knowledge very different from the natural history knowledge and technical knowledge essential to the welfare of hunter-gatherer societies, and it is as differently motivated from the objectives underlying archaic technology and natural history knowledge as it is from the modern objective of seeking knowledge for its own sake. It amounts to the social construction of reality. As historian of science, H. Floris Cohen argued in his The Scientific Revolution: An Historical Inquiry, our archaic forebears encased their knowledge of the physical, biological, and social knowledge in the "framework of a larger conception of how things in the universe cohere," expressed in stories projecting purpose and meaning into both the animate and inanimate world around them. ${ }^{84}$ They made sense of their world in terms of the intentions of human and non-human agents. The naturalness of this agent-oriented mode of thought, as Donald has pointed out, dominated Upper Palaeolithic, Mesolithic, and Neolithic societies and still persists in some fashion today. As Donald puts it: " $\mathrm{i}[\mathrm{t}$ continues today in many traditions, and its vestiges are still highly visible in some sectors of postindustrial civilization. Its exact outer boundary cannot easily be drawn" ${ }^{85}$ A causality-oriented mode of thought, claims Donald, has, clearly, "become the dominant thought form of postindustrial society" and although it has not wholly displaced religio-mythic thought socially, it undermines its epistemic credibility, a project, as he puts it, that required "a wrenching cultural transformation" ${ }^{86}$ often referred to as a process of demythologization, or disenchantment, of the world.

\section{Conclusion}

The evidence provided by evolutionary cognitive science and the 'pre-history' of H. sapiens clearly supports Mithen's view that "the emergence of science as a discrete domain of behaviour is likely to have required a suite of social, historical and economic circumstances that

\footnotetext{
${ }^{82}$ Donald, Merlin. Origins of the Modern Mind: Three Stages in the Evolution of Culture and Cognition. (Cambridge Mass.: Harvard University Press), 1991, 257.

${ }^{83}$ Ibid.

${ }^{84}$ Cohen, H. Floris. The Scientific Revolution: An Historical Inquiry. (Chicago: University of Chicago Press), 1994, 506.

${ }^{85}$ Donald, Merlin. Origins of the Modern Mind: Three Stages in the Evolution of Culture and Cognition. (Cambridge Mass.: Harvard University Press), 1991, 275.

${ }^{86}$ Ibid.
} 
had not yet arisen in human history [with our archaic forebears]" ${ }^{87}$ And I am persuaded by Donald's claim that the cultural transformation of the human mind, which he refers to broadly as the emergence of the theoretic attitude, occurred in ancient Greece. ${ }^{88}$ Lewis Wolpert also presents a formidable argument in support of the claim that this transformation occurred in ancient Greece. However, unlike Wolpert, I do not believe that what emerged in ancient Greece amounted to what we today think of as science. Wolpert is certainly correct in his claim that "unlike technology or religion," a transition away from and toward a science-like mode of thought originated "only once in history in Greece". 89 Following Karl R. Popper, I believe the evidence will show that the mode of thought developed by the Milesian philosopher-cosmologists amounted to an enlightenment of sorts that ultimately made possible the emergence of a genuinely scientific mode of thought in sixteenth- and seventeenth-century Europe. Proving that matter, however, cannot be taken up here.

\section{Bibliography}

Bulliett, Richard W. Hunters, Herders, and Hamburgers: The Past and Future of Human-Animal Relationships. New York: Columbia University Press, 2005.

Cohen, H. Floris. The Scientific Revolution: An Historical Inquiry. Chicago: University of Chicago Press, 1994.

Dennett, Daniel. From Bacteria to Bach and Back: The Evolution of Minds. New York: W. W. Norton \& Company, 2017.

Donald, Merlin. Origins of the Modern Mind: Three Stages in the Evolution of Culture and Cognition. Cambridge Mass.: Harvard University Press, 1991.

Donald, Merlin. A Mind So Rare: The Evolution of Human Consciousness. New York: W. W. Norton \& Company, 2001.

Dunbar, Robin. The Trouble With Science: Science, Magic, and Religion. London: Faber and Faber, 1995.

Gellner, Ernest. The Savage and the Modern Mind. In Robin Horton and Ruth Finnegan (eds.). Modes of Thought (162-181). London: Faber and Faber, 1973.

Gellner, Ernest. An Ethic of Cognition. In Ernest Gellner, Spectacles and Predicaments: Essays in Social Theory (162-181). Cambridge: University of Cambridge Press, 1979.

Gopnik, Alison, and Andrew N. Meltzoff. Words, Thoughts, and Theories. Cambridge Mass.: MIT Press, 1997. Gopnik, Alison, and Meltzoff, Andrew N., and Patricia K. Kuhl. The Scientist in the Crib: What Early Learning Tells Us About the Mind. New York: Harper Collings, 1999.

${ }^{87}$ Mithen, Steven. Human Evolution and the Cognitive Basis of Science. In Peter Carruthers, Stephen Stitch, and Michael Segal (eds.). The Cognitive Basis of Science (23-40). (Cambridge: Cambridge University Press), 2002, 40.

${ }^{88}$ Donald, Merlin. Origins of the Modern Mind: Three Stages in the Evolution of Culture and Cognition. (Cambridge Mass.: Harvard University Press), 1991, 340.

${ }^{89}$ Wolpert, Lewis. The Unnatural Nature of Science: Why Science Does Not Make (Common) Sense. (Cambridge Mass.: Harvard University Press), 1993, 35. 
Mercier, Hugo, and Daniel Sperber. The Enigma of Reason. Cambridge Mass.: Harvard University Press, 2017.

Mithen, Steven. The Prehistory of the Mind: The Cognitive Origins of Art and Science. London: Thames and Hudson, 1999.

Mithen, Steven. Human Evolution and the Cognitive Basis of Science. In Peter Carruthers, Stephen Stitch, and Michael Segal (eds.). The Cognitive Basis of Science (23-40). Cambridge: Cambridge University Press, 2002.

Popper, Karl R. Back to the Presocratics. In Karl Popper, Conjectures and Refutations: The Growth of Scientific Knowledge. 136-165). New York: Harper and Row, 1965.

Tomasello, Michael. The Cultural Origins of Human Cognition. Cambridge Mass.: Harvard University Press, 1999.

Tomasello, Michael. Origins of Human Communication. Cambridge Mass.: MIT Press, 2008.

Tomasello, Michael. Why We Cooperate. Cambridge Mass.: MIT Press, 2009.

Tomasello, Michael. A Natural History of Human Thinking. Cambridge Mass.: Harvard University Press, 2014.

Tomasello, Michael. Becoming Human: A History of Ontogeny. Cambridge Mass.: Harvard University Press, 2019.

Wolpert, Lewis. The Unnatural Nature of Science: Why Science Does Not Make (Common) Sense. Cambridge Mass.: Harvard University Press, 1993. 